\title{
Factors affecting resolution of pericardial effusions in primary hypothyroidism: a clinical, biochemical and echocardiographic study
}

\author{
A. A. KHALEELI \\ M.B., M.R.C.P. (U.K.) \\ N. MEMON \\ M.B., M.R.C.P. \\ Charles Dent Metabolic Unit and Department of Cardiology, University College Hospital, London WC1
}

\begin{abstract}
Summary
Echocardiography detected pericardial effusions in five out of six consecutive untreated patients with severe primary hypothyroidism and suspected myopathy, whereas the chest X-ray suggested only one. During L-thyroxine replacement, serial echocardiograms detected decrease in the size of the effusions in all the patients. This occurred before the serum thyroid stimulating hormone (TSH) levels had significantly changed, although there was a small but significant rise in serum thyroxine. In one patient complete resolution of the effusion occurred before the patient became euthyroid, a previously unreported finding.

Small voltage complexes, $T$-wave inversion and non-specific $T$-wave flattening were the commonest electrocardiographic abnormalities noted. The former invariably and the latter two abnormalities frequently, reverted to normal before the patient became biochemically and clinically euthyroid. $T$ wave inversion in a particular lead, however, did not invariably do so, suggesting that permanent structural change might possibly have occurred.

The plasma creatine kinase (CK) was raised in four patients, and markedly raised at levels usually associated with muscular dystrophy, in two. At the onset of resolution of the pericardial effusions, the total plasma CK had fallen significantly in all patients in whom it was raised.
\end{abstract}

\section{Introduction}

Gordon (1929) first described pericardial effusions complicating myxoedema. For a long time myxoedema has been known to result in an abnormal heart (Zondek, 1918), premature death from coronary artery occlusion (Fahr, 1925; Douglass and Jacobson, 1957), a low cardiac output state (Amidi et al., 1968), cardiac enlargement (Aber and Thompson, 1963), and cardiomyopathy (Hamilton and Greenwood, 1957).

Echocardiography allows small pericardial effu- sions, undetectable on chest $\mathrm{X}$-ray, to be recognized (Horowitz et al., 1974). The incidence of pericardial effusions in primary hypothyroidism has ranged from 30 to $78 \%$ in different series (Hardisty, Naik and Munro, 1980; Kurtzman, Otto and Chepey, 1965). In the former series complete resolution of the effusion in 9 cases occurred only when the patients had been biochemically euthyroid for some time. We were anxious to determine when the earliest resolution in effusion occurs and the factors that influence this process.

\section{Patients, materials and methods}

Of 6 consecutive hypothyroid patients with muscle symptoms and in 5 cases, electromyography (EMG) or skeletal muscle needle biopsy evidence of myopathy, 5 were shown to have a pericardial effusion and were studied further. All but one were admitted to hospital and after investigations each received a small initial daily dose of L-thyroxine $(0.025 \mathrm{mg}$ in all but one who received $0.0125 \mathrm{mg}$ ) for 2 weeks, increasing gradually thereafter. Primary hypothyroidism was confirmed by finding a low serum thyroxine (normal $=70-160 \mathrm{nmol} /$ litre), low serum triiodothyronine (normal $=1 \cdot 2-2.8 \mathrm{nmol} /$ litre) and a raised serum thyroid stimulating hormone (TSH) (normal = less than 4.2 iu./litre) all measured by radioimmunoassay. These hormones were re-estimated at weekly intervals on hormone replacement. All 6 patients had positive thyroid antibodies (titres greater than $1 / 80^{2}$ to thyroglobulin or thyroid microsomes).

A standard twelve lead electrocardiogram (ECG) with rhythm strip was performed before treatment and regularly till the patient became euthyroid, including every time the dosage of L-thyroxine was changed. Small voltage complexes were defined as deflections of less than $5 \mathrm{~mm}$ in QRS in standard leads I to III, non-specific T-wave flattening as Twaves of amplitude $1 \mathrm{~mm}$ or less and sinus bradycardia as a pulse rate below $60 / \mathrm{min}$. Other 
abnormalities including previous cardiac infarcts, were noted.

Echocardiography using a standard ultrasonoscope with a continuous recorder (SKI Ekoline 21) was performed by skilled personnel. A diagnosis of pericardial effusion was made only when both anterior and posterior effusions were present as shown by an echo-free space of more than $3 \mathrm{~mm}$. Frequent serial recordings during thyroxine replacement were made till the patient became euthyroid, and in 4 cases until the effusion resolved. The findings were reported by N.M. Onset of resolution was defined as the first definite visible reduction in the size of the effusion on serial echocardiograms. Although a subjective impression, this finding in each patient was subsequently confirmed by two independent cardiologists who were given the echocardiograms blind and in random order. The time taken for the disappearance of either the posterior or anterior effusion was also noted as was the period for the effusion to resolve completely.

A chest X-ray using a 6-foot PA film was performed on all untreated patients. Total plasma creatine kinase (CK) was measured on unhaemolysed plasma at $37^{\circ} \mathrm{C}$ using Boëhringer optimized kits with a glutathione activator. The mean of three measurements are quoted. The normal range is 10-120 i.u./litre. The estimations were repeated weekly during hormone replacement till the patient became euthyroid.

\section{Results}

Table 1 summarizes the clinical, biochemical and cardiac findings before and after treatment. Only case 2 had cardiomegaly on chest $X$-ray. This resolved on treatment. There were no significant changes detectable in pulse rate or blood pressure over the period of the study except in the sole patient with a bradycardia whose heart rate rose from 56 to 75 per min over the period of 3 weeks before any detectable resolution was noted in the size of her pericardial effusion or in the electrocardiographic abnormalities.

Figure 1 shows the serum thyroxine (T4) and $\hookrightarrow$ serum TSH in our hypothyroid patients before and $\overrightarrow{\bar{S}}$ during treatment and their relationship to the onset $\overrightarrow{0}$ of resolution and eventual disappearance of the $\frac{c}{0}$ pericardial effusions. It can be seen that the onset of $\overline{\bar{m}}$ resolution of the pericardial effusions occurred in all our patients before they were biochemically euthyroid (mean serum TSH was 41 i.u./litre, mean serum is thyroxine was $44 \mathrm{nmol} /$ litre) and in one patient the $\overrightarrow{0}$ effusion had gone before he was clinically or $\overrightarrow{-}$ biochemically euthyroid. All of our patients showed $\vec{\omega}$ complete resolution of their effusions with treatment. The mean duration of treatment before onset of resolution was 34 days (range 16-64 days), before resolution of either anterior or posterior effusions was 108 days (range 21-304 days) and before complete resolution was 162 days (range 70-370 days, excluding the patient who went abroad for 9 months).

The mean plasma CK before treatment was 1525 i.u./litre and at the onset of resolution of the effusions was 399 i.u./litre. In all but one patient whose plasma CK was 129 i.u./litre, the plasma CK was well below the upper limit of normal when the effusions had disappeared. In two patients with verd high levels of plasma $C K$ the cardiac isoenzymes (MB) was measured using Boëhringer kits. In these two patients (patients III and IV) the cardiac CK was only 72 and 80 i.u./litre (normal 0-50 i.u./litre) compared to total plasma CK values of 4640 and $1866 \mathrm{i} . \mathrm{u} . /$ litre in the two patients.

\section{Discussion}

Resolution of the effusions in all of our patients started very early and this finding has not previously been emphasized and is contrary to the findings of Hardisty, Naik and Munro (1980) where all patients followed were euthyroid before resolution started.

TABLE 1. Clinical, biochemical and cardiac investigations before and after treatment in five hypothyroid patients with pericardial effusion

\begin{tabular}{|c|c|c|c|c|c|}
\hline Patients (sex and age in years) & I (F51) & II (F56) & III (M64) & IV (F70) & V (F76) \\
\hline $\begin{array}{l}\text { Length of history of myxoedema (years) } \\
\text { Previous myocardial infarct } \\
\text { Heart rate/min } \\
\text { Blood pressure (mm } \mathbf{H g} \text { ) } \\
\text { Heart failure/pulsus paradoxus } \\
\text { ECG- }\end{array}$ & $\begin{array}{l}8 \\
\text { No } \\
65 \\
120 / 70 \\
\text { No }\end{array}$ & $\begin{array}{l}4 \\
\text { No } \\
56 \\
120 / 75 \\
\text { No }\end{array}$ & $\begin{array}{l}3 \\
\text { No } \\
72 \\
130 / 80 \\
\text { No }\end{array}$ & $\begin{array}{l}3 / 4 \\
\text { No } \\
78 \\
180 / 100 \\
\text { No }\end{array}$ & $\begin{array}{l}2 / 3 \\
\text { Yes } \\
72 \\
170 / 80 \\
\text { No }\end{array}$ \\
\hline $\begin{array}{l}\text { small QRS complexes* } \\
\text { flat/inverted T-waves } \\
\text { Plasma CK (i.u./litre) at onset of resolution } \\
\text { (untreated plasma CK in brackets) } \\
\text { Number of echocardiograms }\end{array}$ & $\begin{array}{c}\text { Yes/Yes } \\
\text { Yes/Yes } \\
406(639) \\
6\end{array}$ & $\begin{array}{l}\text { Yes/Yes } \\
\text { Yes/Yes } \\
37(445) \\
10\end{array}$ & $\begin{array}{l}\text { Yes/Yes } \\
\text { Yes/Yes } \\
406(4640) \\
5\end{array}$ & $\begin{array}{c}\text { Yes/Yes } \\
\text { Yes/No } \\
1110(1866) \\
7\end{array}$ & $\begin{array}{l}\text { No/- } \\
\text { Yes/- }\end{array}$ \\
\hline
\end{tabular}

*Present untreated/resolved before TSH $<4 \cdot 2$ i.u./litre. 

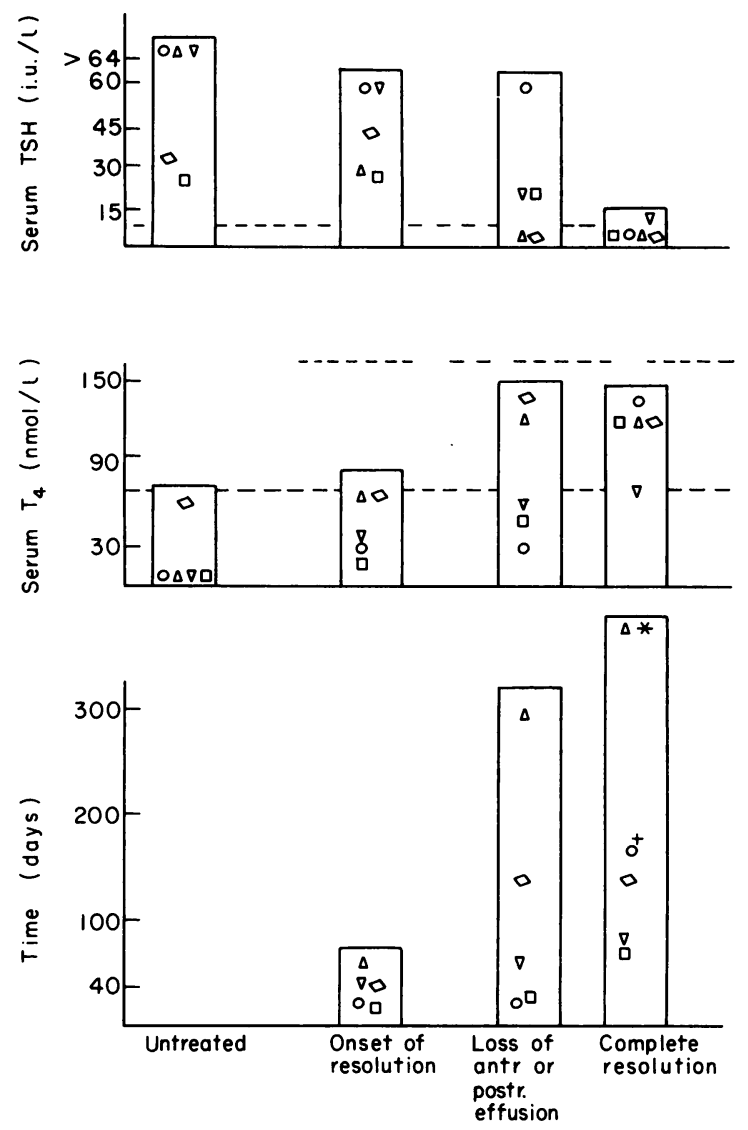

FIG. 1. Relationship between serum TSH and T4 and resolution of pericardial effusions in five patients with hypothyroidism. $---=$ normal range; $+=>100$ but $<400$ days; ${ }^{*}=370$ days.

Our study, involving numerous echocardiographic recordings, was designed principally to detect when the earliest change occurred. We were anxious to exclude bias and technical factors which might account for the findings and thus the echocardiograms were assessed by two independent cardiologists who confirmed our findings.

The finding may be important as it implies that thyroid hormone responsiveness by different tissues can occur at small doses, and be to some extent an individual matter. As our patients were all elderly and one had had a myocardial infarct the dosage of thyroxine initiated was low at $0.025 \mathrm{mg}$ daily. These small doses may have allowed us to detect minor resolution of the effusion, but in one case the effusion disappeared completely before the patient was euthyroid. Myxoedema increases capillary permeability (Lange, 1944) and this may be the cause of the pericardial effusions, which presumably respond to treatment because small doses of thyroxine restore capillary permeability towards normal. Others have found that 'adequate' hormone replacement does this (McGavack, Lange and Schwimmer, 1945). The serum CK which also is thought to reflect changes in membrane permeability in muscle rather than muscle destruction in myxoedema (Doran and Wilkinson, 1975) had significantly fallen when the first evidence of resolution of the effusions had occurred. In the patient whose effusion disappeared before he was euthyroid the plasma CK had fallen tenfold at the onset of resolution. This is not to imply that the fall in total plasma CK is in any way causal to the resolution (as effusions occur in the presence of a normal CK level) but the two processes may have a similar time scale of response to treatment. The finding that the cardiac CK was only just raised whereas total plasma CK was very high implies skeletal muscle is the main source of the raised plasma CK in myxoedema, reflecting the much larger amounts of skeletal muscle comparatively. It is interesting that the plasma $\mathrm{CK}$ fall appeared to precede the fall in TSH and may reflect changes in onset of resolution of effusions more effectively, although unmeasured falls in TSH reported as greater than 64 i.u./litre may have occurred. The serum thyroxine, certainly, had risen significantly when resolution was first detected.

The commonest electrocardiographic abnormalities found were small voltage complexes and $T$-wave flattening or inversion. These changes can occur in the absence of an effusion (Hardisty, Naik and Munro, 1980) though in our patients an effusion occurred in every instance. These abnormalities reverted with treatment in some cases before the pericardial effusion had disappeared on the echocardiogram suggesting a functional rather than a permanent structural change. Sinus bradycardia, so common in myxoedema coma (Khaleeli, 1978) was unusual in our patients and in Hardisty's larger series (Hardisty et al., 1980). This might suggest that myxoedema has to be even more advanced than in our patients before inducing this protective haemodynamic change.

The high incidence of pericardial effusions in our small series probably reflects the clinical and biochemical severity of the myxoedema shown by the very low serum thyroxine and high serum TSH levels, and the high levels of plasma CK (Graig and Smith, 1965). The length of the history of myxoedema before treatment and the high incidence of confirmed concomitant myopathy might imply that chronicity and severity of myxoedema are important. Others, however, have found pericardial effusions in clinically and biochemically mild hypothyroidism (Kerber and Sherman, 1975), but no mention of pericardial effusions together with myopathy in any series occurs in the literature as far as we are aware. 


\section{Acknowledgments}

We are extremely grateful to Professor R. H. T. Edwards and to Dr A. Hollman for allowing us to report on their patients and for their advice and criticism. We are also indebted to Miss $M$ O'Sullivan and Miss M. St Guillaume for their expert technical help with the echocardiograms, to Dr D. Patterson and Dr R. Vecht for checking our echocardiographic findings, the Metabolic, Biochemistry and Cardiac Departments for their assistance and Mrs B. RookeLey for typing the manuscript.

\section{References}

ABER, C.P. \& THOMPSON, G.S. (1963) Factors associated with cardiac enlargement in myxoedema. British Heart Journal, 25, 421.

Amidi, M., Leon, D.F., DE Groot, W.J., KroetZ, F.W. \& LEONARD, J.J. (1968) Effect of thyroid hormone on myocardial contractility and ventricular ejection rate in man. Circulation, 38, 229.

DoRAN, G.R. \& WiLKInSON, J.H. (1975) The origin of the elevated activities of creative kinase and other enzymes in the sera of patients with myxoedema. Clinica chemica acta, 62, 203.

Douglass, R.D. \& JACOBSON, S.D. (1957) Pathological changes in adult myxoedema: survey of 10 necropsies. Journal of Clinical Endocrinology and Metabolism, 17, 1354.
FAHR, G. (1925) Myxoedema heart. Journal of the American Medical Association, 84, 345.

GoRDON, A.H. (1929) Some clinical aspects of hypothyroidism. Canadian Medical Association Journal, $20,7$.

GRAIG, F.A. \& SMITH, J.C. (1965) Serum creatine phosphokinase in altered thyroid states. Journal of Clinical Endocrinology, 25, 723.

HAMILTON, J.D. \& GREenwOOD, W.F. (1957) Myxoedema heart disease. Circulation, 15, 442.

HaRdisTY, C.A., NaIK, D.R. \& MUNRo, D.S. (1980) Pericardial effusions in hypothyroidism. Clinical Endocrinology, 13, 349.

Horowitz, M.S., SchulTz, C.S., STINSON, E.B., HARRISON, D.C. \& POPP, R.L. (1974) Sensitivity and specificity of echocardiographic diagnosis of pericardial effusion. Circulation, 50, 239.

KERBER, R.E. \& SHERMAN, B. (1975) Echocardiographic evaluation of pericardial effusion in myxoedema: incidence and biochemical and clinical complications. Circulation, 52, 823.

KhAleEl, A.A. (1978) Myxoedema coma. A report on five successfully treated cases. Postgraduate Medical Journal, 54, 825.

KuRTZMAN, R.S., OtTo, D. \& ChePEY, J.J. (1965) Myxoedema heart disease. Radiology, 84, 624.

LANGE, K. (1944) Capillary permeability in myxoedema. American Journal of Medical Science, 208, 5.

MCGavaCK, T.H., LANGE, K. \& SChWimmer, D. (1945) Management of the myxoedematous patient with symptoms of cardiovascular disease. American Heart Journal, 29, 421.

ZONDEK, H. (1918) Das Myxödemherz. Münchener medizinsche Wochenschrift, 65, 1180. 